occupational caused by UV, and provides support for the applications of the relevant ILO instruments in member States.

\section{RADIOLOGICAL LICENSE TYPE I-C INSTALLATIONS IN MEXICO}

AL Fajardo Montiel, HU Ramirez Sánchez, AR Meulenert Peña. Universidad de Guadalajara, Guadalajara Jalisco México

\subsection{6/oemed-2018-ICOHabstracts. 1217}

Introduction To carry out the licensing process for facilities classified as Type C, in Mexico, the Procedure:Manual on Radiological Safety must be submitted to the COMISION DE SEGURIDAD NUCLEAR Y SALVAGUARDAS (CNSNS) Nuclear Radiological Safety National Comission which should include general specifications of the installation, to demonstrate that the characteristics of Radiological safety are according with the requirements and include a radiation safety policy, which will apply during the operation, the termination of operations.

Methods According with the Mexican standard and the CNSNS the company should work to implement all the procedures and requirements, first stage include paperwork and external training, the next stage include implementation policies and internal audit, all the documents are send to de government an external visit could be request to demonstrate all the requirements.

Results The radiological safety program will be successful according to the proposed activity risk analysis and emergency plan, and include a failure analysis. With an adequate implementation program, health and environmental radiological monitoring program the organisation should determinate potential risk to release radioactive material out of the facility, and demonstrate that radiological risks resulting from the cessation of operations will be appropriately managed in such a way as to ensure the safety of personnel occupationally exposed, the public and the environment

Conclusion With an adequate program the company will be able describe the design aspects, engineering works, systems, equipment and devices that allow safety operations with radiation sources and minimise the exposure of personnel to radiation and the production of radioactive waste, Containment necessary to limit the release of radioactive material. Estimate dose equivalents, exposure routes and exposed personnel medical control.

\section{OCCUPATIONAL EXPOSURE TO RADON: AN UNDERESTIMATED RISK IN VIEW OF THE COMBINED EXPOSURE TO OTHER OCCUPATIONAL AND ENVIRONMENTAL LUNG CARCINOGENS}

C Grandi*, F Sanjust. INAIL - Dept. of Occupational and Environmental Medicine, Epidemiology and Hygiene, Monte Porzio Catone (RM), Italy

\subsection{6/oemed-2018-ICOHabstracts. 1218}

Introduction Radon is a well-established human carcinogen, targeting the lung. A lot of epidemiological studies conducted on both uranium miners and general population in dwellings provided a risk quantification due to radon exposure, by alone and in combination with tobacco smoke. However, little is known about the risk due to combined exposure to radon and other occupational and environmental lung carcinogens.
Methods Literature review to identify the most critical scenarios of combined exposure to radon and other lung carcinogens, providing a framework for the risk assessment and addressing the planning of epidemiological studies.

Results The combined exposure to radon and other lung carcinogens may be relevant for several indoor working environments. However, it is important to keep in mind that for a number of workers a combined exposure may occur in a sequential way, i.e. to radon in indoor settings and to outdoor carcinogens if the job/s are conducted at least in part outdoor. Apart the tobacco smoke, co-exposures of interest include asbestos, crystalline silica, polycyclic aromatic hydrocarbons, hexavalent chromium, nickel and outdoor air pollution, all extensively assessed in both epidemiological and/or experimental studies.

Discussion Prevention of lung cancer occurrence in radonexposed workers has not only to take into account the longterm indoor radon concentrations, as obtained by conventional dosimetric assessment, and the smoking status of the worker, but must include an accurate assessment of the patterns of exposure to other lung carcinogens, both ubiquitous and typical of a particular occupational or living setting. Unfortunately, validated biomarkers of exposure, early biological effect/s and individual susceptibility are not available in this regard and different lung carcinogens display different kinetics and may act through several distinct (although partly overlapping) cellular and molecular pathways, both genetic and epigenetic. The development of 'omics' approaches represent a promising tool to address this topic.

\section{EXPOSURE TO STATIC MAGNETIC FIELDS AND DISTURBANCES OF ACTIVE IMPLANTABLE MEDICAL DEVICES}

${ }^{1} \mathrm{R}$ Pääkkönen, ${ }^{2} \mathrm{~L}$ Korpinen*. ${ }^{1} T M I$ Rauno Pääkkönen, Tampere, Finland; ${ }^{2}$ Clinical Physiology and Neurophysiology Unit, The North Karelia Central Hospital, Joensuu, Finland

\subsection{6/oemed-2018-ICOHabstracts. 1219}

Introduction According to Directive 2013/35/EU for magnetic fields from 0 to $1 \mathrm{~Hz}$, the exposure limit value (ELV) for sensory effects due to magnetic flux density is $2 \mathrm{~T}$ (Tesla) and 8 $\mathrm{T}$ for limbs. Interference with active implanted devices, e.g., cardiac pacemakers, starts at an action level (AL) of $0.5 \mathrm{mT}$. Interference can influence the functioning of medical devices. The aim is to describe some examples of static magnetic field exposure and calculations to evaluate the possible risk of disturbances to medical devices.

Methods We measured and analysed field values on the surface of magnetic objects and how the exposure to static magnetic fields decreased when the distances of the source increased. The used metres were based on Hall effect sensors; Holaday Industries HI 3550 or Extech MF100. Then, we compared theoretically measured values to the abovementioned directive levels.

Results Static magnetic flux density can be high (e.g., 20-200 $\mathrm{mT}$ ) at the surfaces of magnets, and magnetising fields can be very high $(0.5-3 \mathrm{~T})$. However, the distance attenuation decreases the flux rapidly; for example, at a distance of $1 \mathrm{~cm}$ from the cable, the field can be $2.5 \mathrm{mT}$ (shielded cable, current $400 \mathrm{~A}$ ), but at a distance of $10 \mathrm{~cm}, 0.5 \mathrm{mT}$ ( $\mathrm{AL}$ for active implanted devices), and $30 \mu \mathrm{T}$ at a distance of $1.0 \mathrm{~m}$. 